\title{
A Novel Compact and Wideband Multi U-Slotted Microstrip Antenna
}

\author{
J. Chandrasekhar Rao ${ }^{1}$, K.Pradeep Rajashekar ${ }^{2}$, G. Rajendra Babu ${ }^{3}$ and K. \\ Sandhya ${ }^{4}$ \\ ${ }^{1}$ Assistant Professor, Department of ECE, $K$ L University, A.P, India. \\ ${ }^{2,3,4}$ UG student, Department of ECE, St. Ann's College of Engineering \& \\ Technology, Chirala, A.P India \\ jettychandu@gmail.com
}

\begin{abstract}
A new compact and wideband multi $U$-slotted microstrip patch antenna with improved bandwidth is presented in this paper. The antenna is resonating at the center frequency of $4.2 \mathrm{GHz}$ with return loss of $-40 \mathrm{~dB}$. The proposed antenna provides an impedance bandwidth of $110 \%$ and VSWR $\leq 1.02$ which is close to mity, The proposed antenna is excited by coaxial feed and analyzed by using HFSS software. The proposed multi $U$ slotted microstrip antenna is suitable for Bluetooth, Wi-Fi, WLAN, WiMax wireless communications.
\end{abstract}

Keywords: Coaxial feed, Impedance bandwidth, Microstrip slot antenna, Return loss, VSWR

\section{Introduction}

With tremendous growth in wireless communications technology since many decades, the design of compact, low profile, and videband antennas for wireless communications is a major challenge for antenna design researchers. Microstrip patch antennas are commonly used in wireless communications like Bluetooth, Wi-Fi, WLAN, WiMax applications. In viem of their attractive features such as conformal nature, easy to feed and design, low fabrication cost, robust nature, less weight, and easy to integrate with monolithic microwave integrated circuits (MMIC). However, standard microstrip patch antennas cannot satisfy the bandwidth requirements for most wireless communication systems because of heir narrow bandwidth. This inherent drawback poses design challenge for the microstrip antenna designer to meet the requirements of wireless communication $[1,2]$. Recently, various methods have been proposed to enhance the bandwidth of the microstrip antenna which includes the use of thicker substrates, use of differentpatch shapes, use of various impedance matching and feeding techniques, use of stacked microstrip patches and parasitically coupled or gap-coupled patches, the use of shorting pins and slots on the patch [3-14]. Use of thicker substrate between the patch and gound plane will substantially increase the bandwidth of the microstrip antenna [3]. Uniortunately, using thick substrate will cause surface wave modes that will increase mutual coupling in antenna arrays. Microstrip antenna with different patch shapes also increases the bandwidth. Ge Y et al., proposed E-shaped patch antennas to enhance the bandwidth for high-speed wireless networks [4]. In [5], Ali et al., presented W-shaped patch antenna to improve the bandwidth for wireless communications. Type of feeding technique also affects the bandwidth parameter of antenna. Probe fed stacked patch antenna to increase bandwidth for wideband applications is reported in [6]. In [7-9], Ansari et al., proposed a broadband stacked U-slot microstrip patch antenna, gap-coupled 
or parasitically stacked annular ring microstrip antenna, and shorting pin loaded half disk patch antenna to improve the impedance bandwidth for wideband communications.

Several slot antennas with different shapes such as H-slot, E-slot, L-slot and U-slot are presented to enhance the bandwidth of the antenna in [10-13]. Microstrip square shaped ring slot antenna filled by an H-shape slot for UWB applications is investigated in [10]. This structure is fed by a single microstrip line with a fork like-tuning stub provides the bandwidth of $19 \%$. In [11], authors proposed E-shaped slot antenna which is fed by CPW and microstrip line providing bandwidth of nearly $140 \%$. Non-symmetric ground $\lambda / 4$ open slot antenna for wideband operation is reported in [12]. Broadband asymmetric u-slot patch antenna with narrow probe to enhance bandwidth for wideband communications is reported in [13]. Impedance bandwidth of $30 \%$ is obtained from this design. Vedaprabhu et al., proposed an antenna which uses a patch antenna with two U-shaped slots to achieve dual band operation along with wideband characteristics [14]. In this paper, a novel multi U-slotted microstrip patch antenna with improved bandwidth is presented. Many $U_{-}$ shaped slots are introduced on a single patch to improve the bandwidth. The designed antenna is resonating at the center frequency of $4.2 \mathrm{GHz}$. The return loss of $-40 \mathrm{~dB}$ is obtained from the designed structure with improved impedance bandwidth of $110 \%$ and acceptable VSWR of $\leq 1.02$ which is close to unity. The proposed antenna is led coaxial feed and results are analyzed by using HFSS software The proposed antenna is best suitable for wireless communication technologies.

\section{Proposed Multi U-Slot Antenna Design}

The proposed antenna has been designed with six individual U-slots with varying dimensions on a single patch to work at $4.2 \mathrm{GHz}$ resonating frequency. A single U-slotted antenna has been previously reported winch provides an impedance bandwidth of $30 \%$. The slots are arranged on the pateh such that three U-slots face other three U-slots as shown in the Fig 1. FR4 is used as the substrate with the thickness of $5 \mathrm{~mm}$ which has the dielectric constant value of $c_{r}=4$. The antenna is given coaxial feed with appropriate inner and outer conductor radius of $2 \mathrm{~mm}$ and $3.8 \mathrm{~mm}$ respectively. The position of feed is placed at left-bottom coner of the patch having spacing of $5 \mathrm{~mm}$ from each side. The dimensions of the patch and the slots are mentioned in the Table 1.

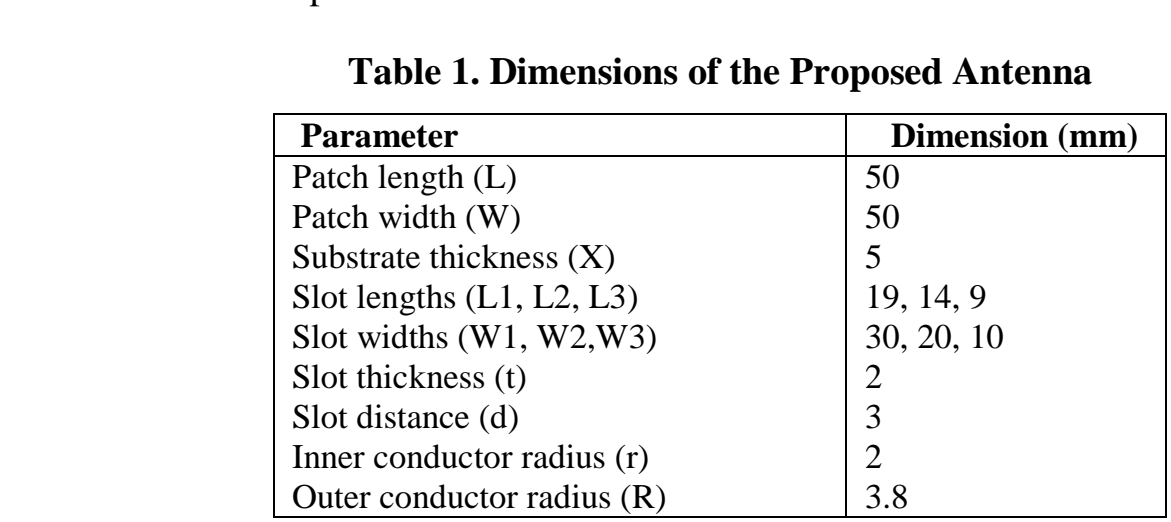




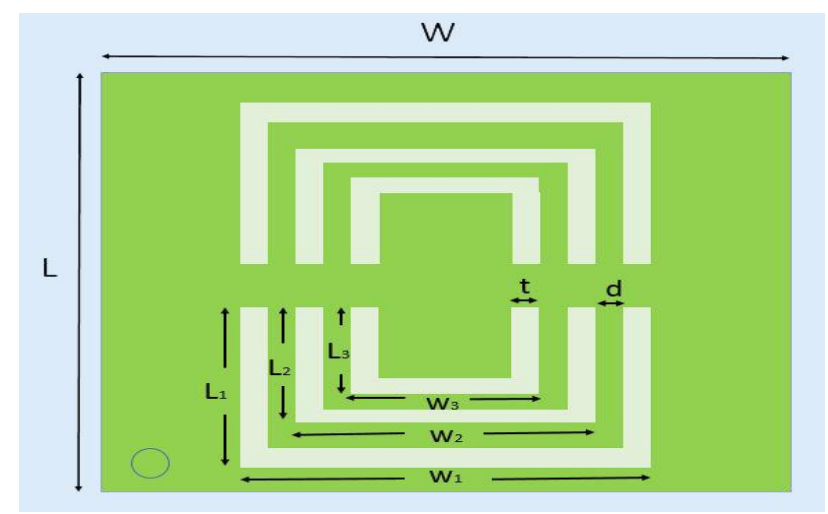

Figure 1. Geometry of Proposed Multi U-slotted Antenna (Top view)

\section{Results and Discussions}

The design of proposed multi U-slotted microstrip antenna using Ansøft' MFSS is shown in Figure 2. The microstrip antenna parameters such as retuen loss, Voltage Standing Wave Ratio (VSWR), radiation patterns, an E-freld and $\mathrm{H}$-field cistributions are discussed and analysed in the subsequent sections using the HFSS software.

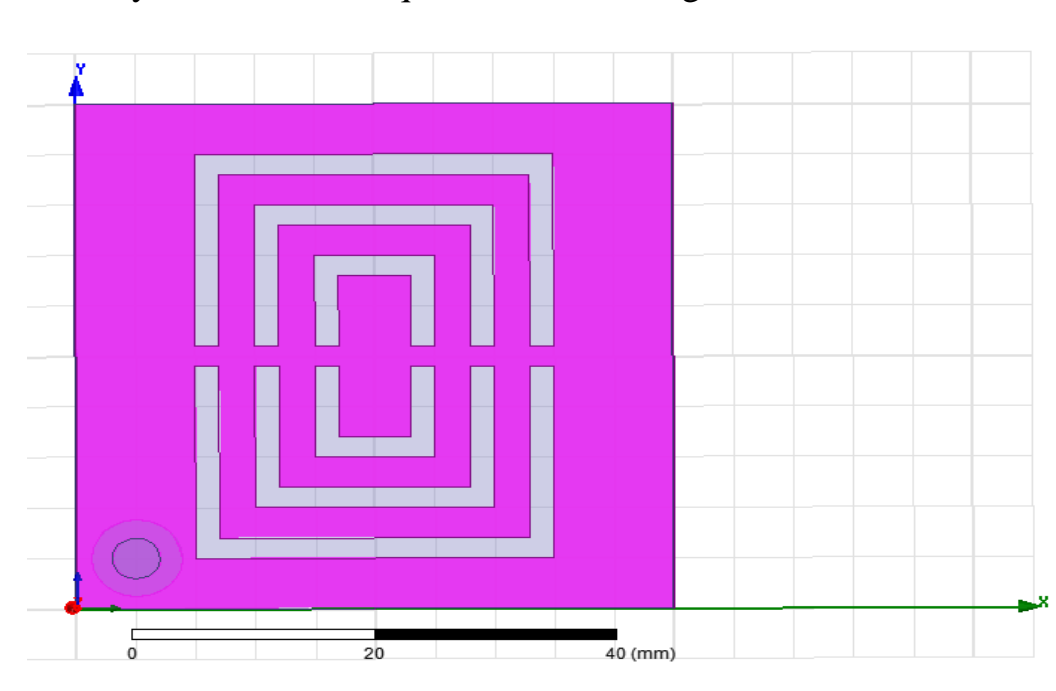

Figure 2. HFSS Design of Proposed multi U-slotted Antenna

\subsection{Return Los}

Return loss is the ratio of amount power reflected to the power delivered generally represented innegative logarithmic $\mathrm{dB}$. The minimum the return loss better the antenna performance. The return loss plot of the designed antenna is shown in the Figure 3. The proposed antenna is resonating at the center frequency of $4.2 \mathrm{GHz}$. From the return loss plot, it is observed that $-40 \mathrm{~dB}$ of return loss is obtained from the proposed multi U-slotted antenna. 


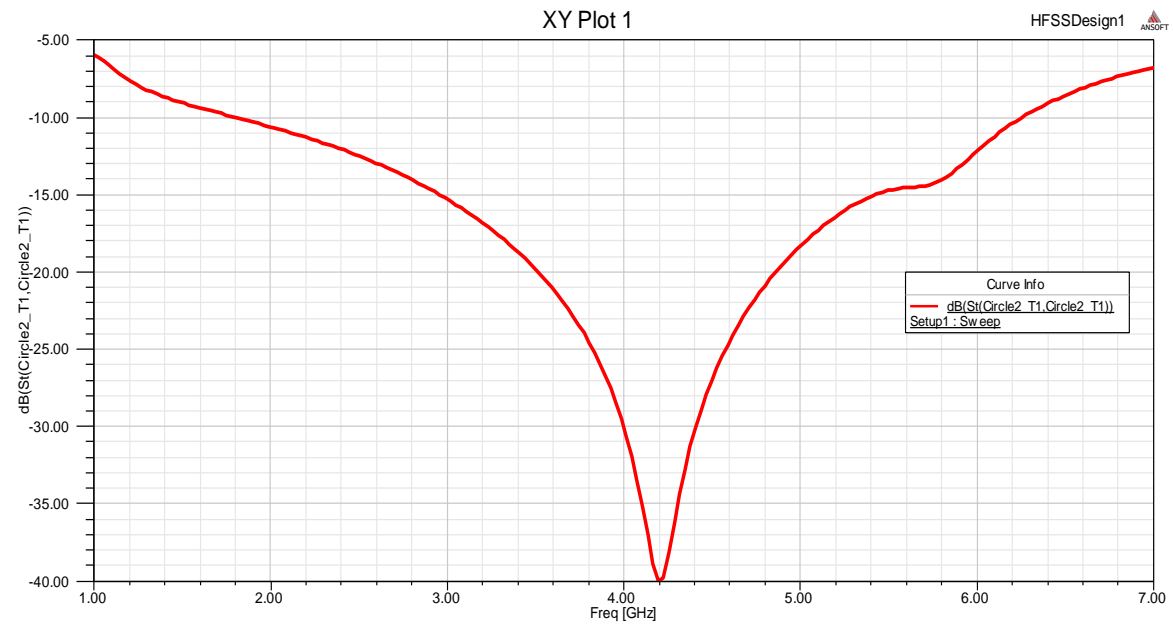

Figure 3. Return Loss Plot of Proposed Multi U-slotted Antenna

The impedance bandwidth can be measured from the return loss plot of the antenna. Impedance bandwidth of $110 \%$ is obtained from the proposed multi U-slotted antenna which is very better than previously proposed slot antennas. The bandwidth is measured between the frequencies from $1.8 \mathrm{GHz}$ to $6.2 \mathrm{GHz}$ which $18110 \%$ as observed from Figure 3.

\subsection{VSWR}

The VSWR is a measuring parameter which indicates the impedance mismatch between the antenna and the transmission line Higner the VSWR, greater is the mismatch. VSWR of close to unity is recommended for most wireless communications. The plot between VSWR and frequency of operation is shown in Figure 4. From the VSWR plot, the VSWR of proposed multi U-slotted antenna is observed to be $\leq 1.02$ which is almost equal to unity.

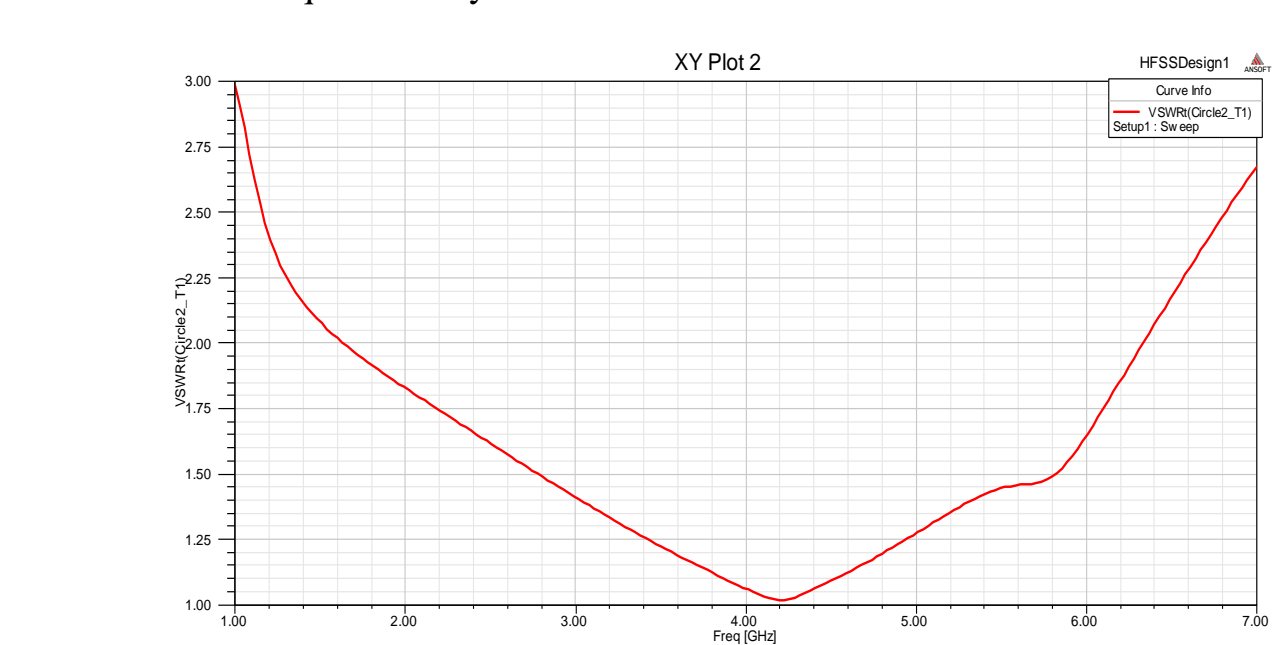

Figure 4. VSWR Plot of Proposed multi U-slotted Antenna

\subsection{Radiation Pattern}

Radiation pattern is the graphical representation radiation properties of the antenna and it shows the variation of power radiated by the antenna as a function of the direction. The radiation pattern also represents the relative strength of the radiated field in different directions from the antenna, at a constant distance. Radiation pattern of proposed multi Uslotted antenna is shown in Figure 5. The radiation characteristics of the designed antenna 
is represented by the $2 \mathrm{D}$ radiation pattern at $\mathrm{Phi}=0 \mathrm{deg}, \mathrm{Phi}=90$ deg for all theta as observed from the Figure 5.

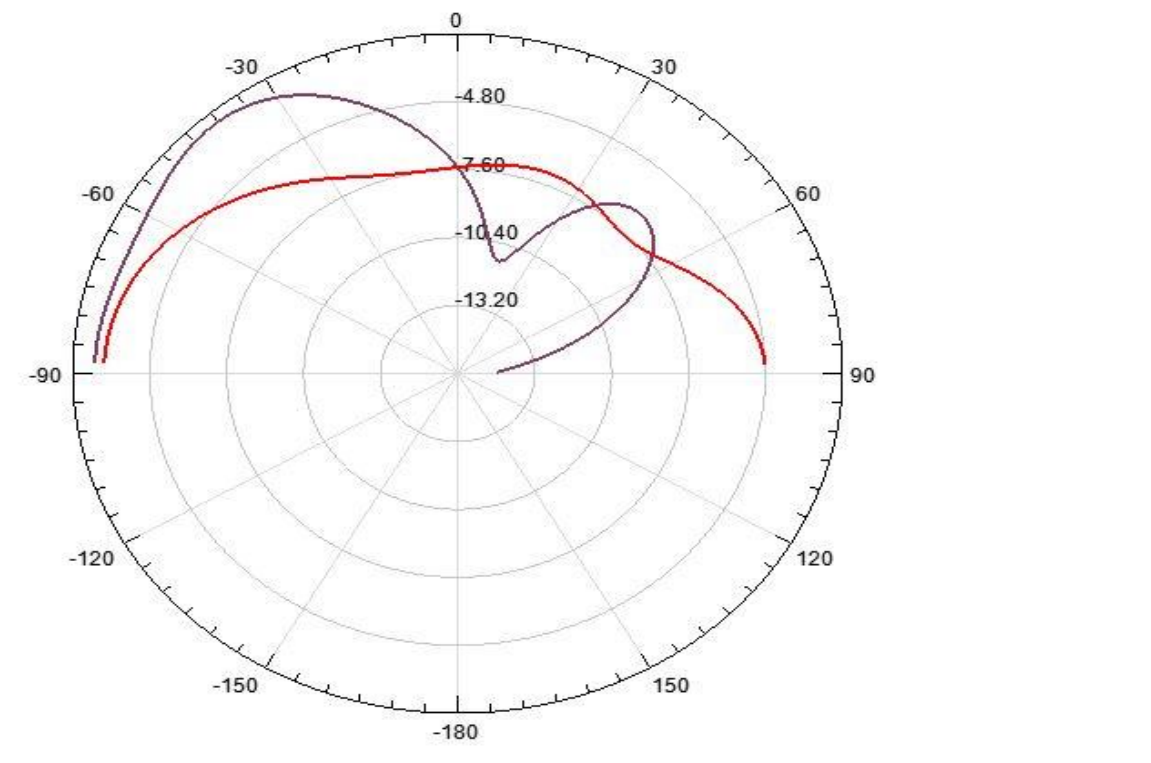

Figure 5. Radiation Pattern of Proposed Multi U-siotted Antenna

\subsection{Electric-field Distribution}

The electric field distribution on the surface the patcb describes the direction of electric field lines at each point in the field. Usually, the path of the electric field lines is from positive to negative charged points. The electric freld (E-field) plot for the proposed multi U-slotted antenna is shown in the Figure 6.

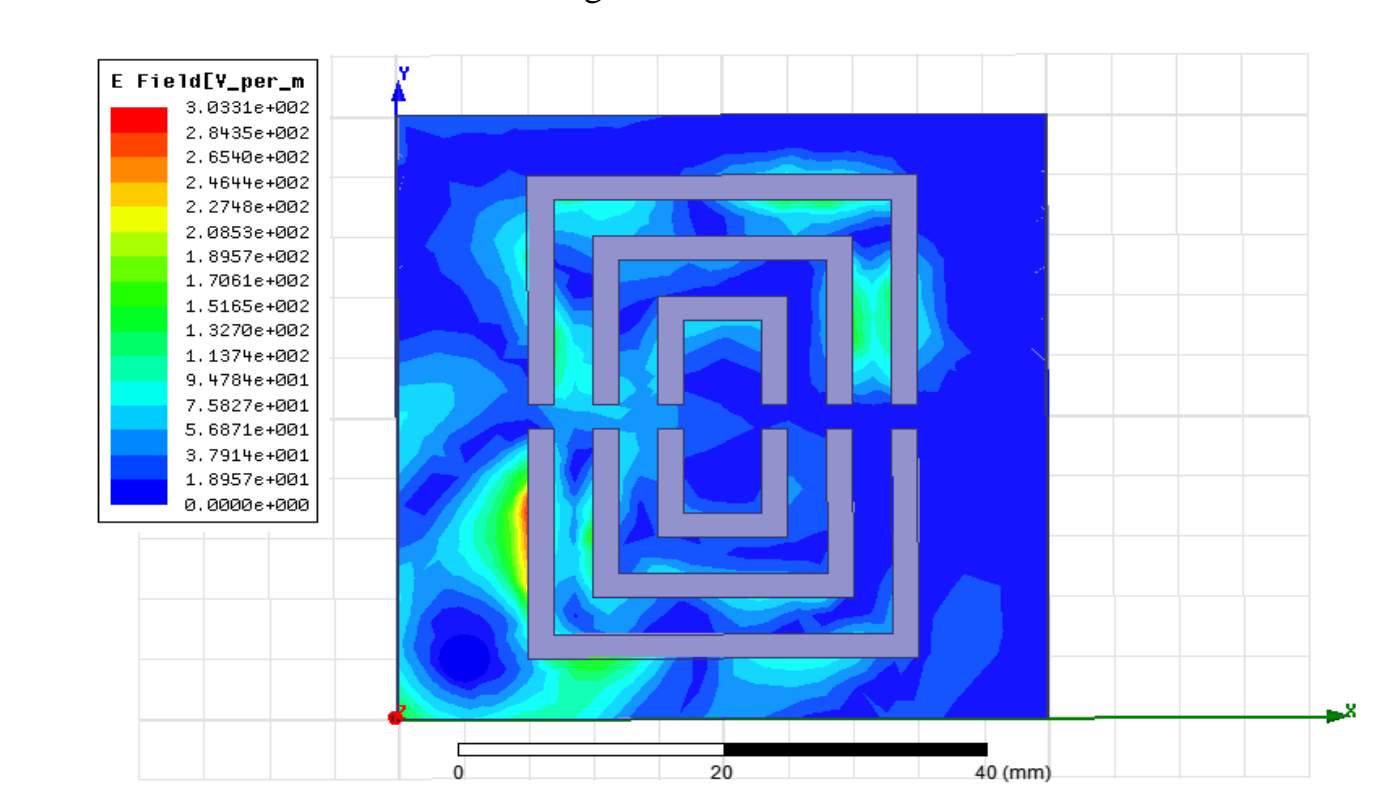

Figure 6. E-field Pattern of Proposed Multi U-slotted Antenna

\subsection{Magnetic-field Distribution}

The magnetic-field (H-field) distribution on the surface of the patch determines the direction of magnetic field vector. The $\mathrm{H}$-field vector always assumes 90 degree angle direction to that of the electric field. The $\mathrm{H}$-field plot for the proposed multi U-slotted antenna is shown in the Figure 7. 


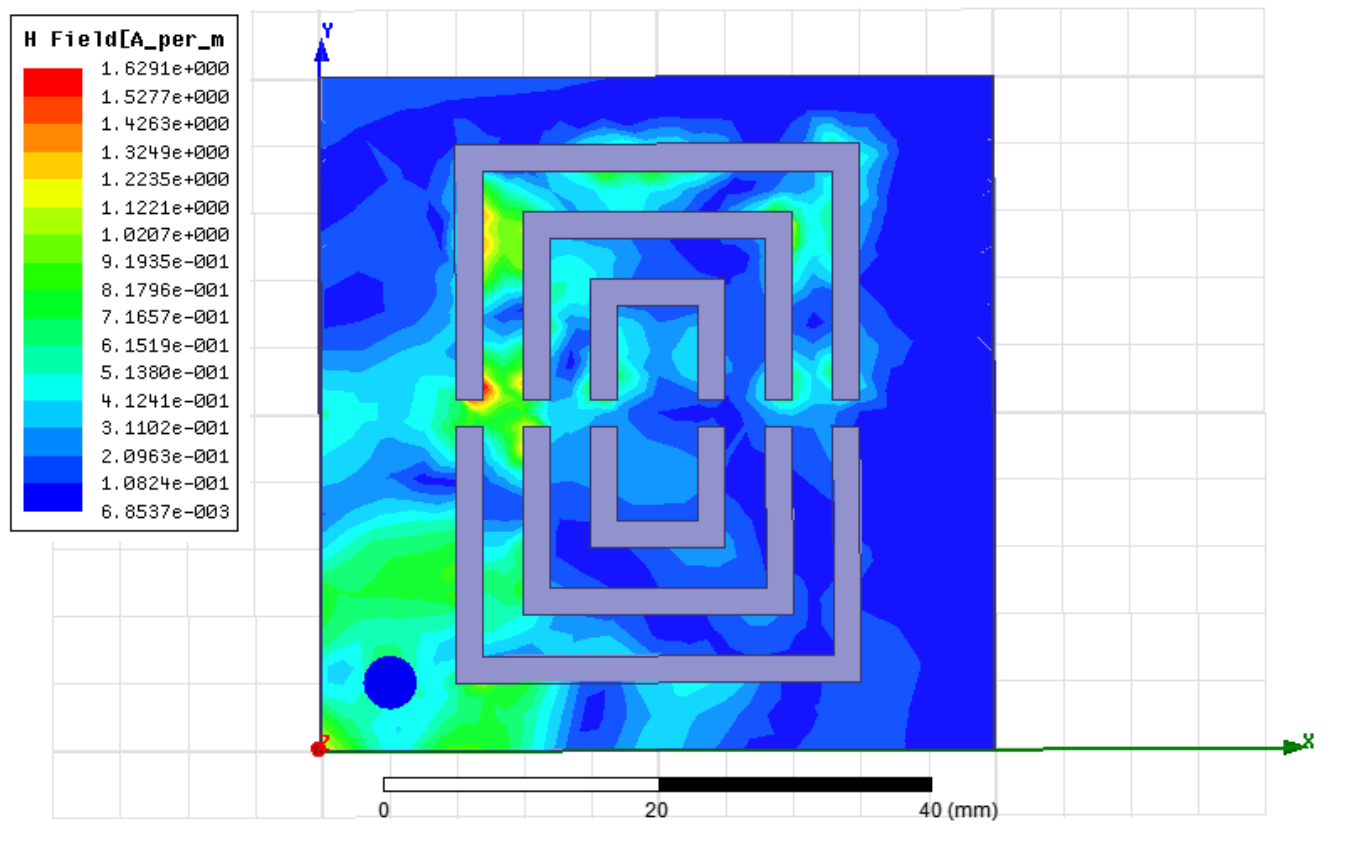

Figure 7. H-field Pattern of Proposed muiti U-slotted Antenna

\section{Conclusion}

In this paper, a new design method namely multi U-slotted-microstrip patch antenna to enhance impedance bandwidth presented. Six U-shaped slots are introduced on a single patch of the antenna to improve the bandiyidth. The designed antenna is resonating at the center frequency of $4.2 \mathrm{GHz}$. The return loss of $-40 \mathrm{~dB}$ is obtained from the designed structure with improved impedancebandwidtit of $110 \%$ and acceptable VSWR of $\leq 1.02$ which is close to unity. The proposed antenna is fed coaxial feed and results are analyzed by using HFSS software. The proposed antenna is best suitable for wireless communication technologies. The proposed multi U-slotted microstrip antenna is suitable for Bluetooth, Wi $\mathrm{Fi}$ WLAN, WiMax wireless communications.

\section{Acknowledgements}

The authors would like to thank to the management of K L University and St. Ann's College of Engineering \& Technology and also to the Departments of Electronics and Communication Engieering for their continuous support and encouragement during this work.

\section{References}

[1] Yang, X.-X. Zhang, X. Ye and Y. Rahmat-Samii, "Wide-band E-shaped patch antennas for wireless communications", IEEE Transactions on Antennas and Propagation, vol. 49, (2001) July 7, pp. 109100 .

[2] R. Garg and P. Bhartia, "Microstrip antenna handbook", Artech house, Boston, (2001).

[3] J. R. James and P. S. Hall, "Handbook of Microstrip Antennas", Peter Peregronic Ltd., London, (1989).

[4] Y. Ge, K. P. Esselle and T. S. Bird, "E-Shaped patch antennas for high-speed wireless networks", IEEE Transactions on Antennas and Propagation, vol. 52, (2004) December 12, pp. 3213-9.

[5] A. Ali and L. Neyestanak, "W-shaped enhanced bandwidth patch antenna for wireless communication", Wireless Pers. Communication, vol. 43, (2007), pp. 1257-1265.

[6] M. M. Matin, B. S. Sharif and C. C. Tsimenidis, "Probe fed stacked patch antenna for wideband applications", IEEE Transactions on Antennas and Propagation, vol. 55, no. 8, (2007), pp. 385-2388.

[7] J. A. Ansari and R. B. Ram, "Broadband stacked U-slot microstrip patch antenna", Progress In Electromagnetics Research Letters, vol. 4, (2008), pp. 17-24.

[8] J. A. Ansari, R. B. Ram and P. Singh, "Analysis of a gap-coupled stacked annular ring microstrip antenna”, Progress In Electromagnetics Research B, vol. 4, (2008), pp. 147-158. 
[9] J. A. Ansari, P. Singh, N. P. Yadav and B. R. Vishvakarma, "Analysis of shorting pin loaded half disk patch antenna for wideband operation”, Progress In Electromagnetics Research C, vol. 6, (2009), pp. 179-192.

[10] S. Sadat, M. Houshmand and M. Roshandel, "Design of a microstrip square-ring slot antenna filled by an H-shape slot for UWB”, Progress in Electromagnetics Research, vol. 70, (2007), pp. 191-198.

[11] A. Dastranj and H. Abiri, "Bandwidth enhancement of printed E-shaped slot antennas fed by CPW and microstrip line", IEEE Transactions on Antennas and Propagation, vol. 58, no. 4, (2010) April.

[12] W. S. Chen and K. Y. Ku, "Broadband design of non-symmetric ground $\lambda / 4$ open slot antenna with small size", Microwave Journal, vol. 50, (2007), pp. 110-121.

[13] G. F. Khodaei, "A practical miniaturized u-slot patch antenna with enhanced bandwidth", Progress In Electromagnetics Research B, vol. 3, (2008), pp. 47-62.

[14] Vedaprabhu, "A Double U-slot Patch Antenna with Dual Wideband Characteristics", Microwave Laboratory, ECE Dept., Indian Institute of Science, Bangalore, India.

\section{Authors}

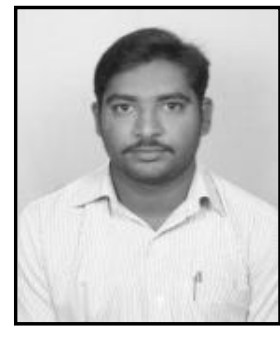

J. Chandrasekhar Rao, was born in India, A.P in 1985. He received his B. Tech, M.Tech degrees in ECE. He is currently working as Assistant professor in ECE department of K LU niversity. He has 4 national conference papers. and 6 international journal publications. His research interests include microstip antennas, image processing and microprocess ors.

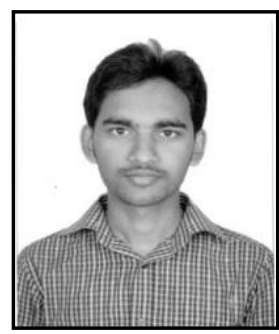

K. Pradeep Rajashekar, was born Iin 1993 at Guntur District, Andhra Pradesh state India. He Graduated in Electronics and Communication Engineering from St. Ann's college of Engineering \& Technology College which is affiliated to JNTU Kakinada University, Chirala.

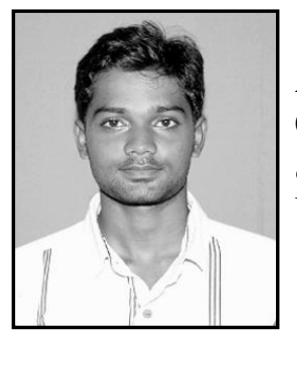

G. Rajendra Babu, was born in 1993 at Prakasham District, Andhra Pradesh state, India. He Graduated in Electronics and Communication Engineering from St. Ann's college of Engineering \& Technology College which is affiliated to JNTU Kakinada Unversity, Chirala.

K. Samdhya, was born in 1993 at Prakasham District, Andhra Pradesh state, India. She Graduated in Electronics and Communication Engineering from St. Ann's college of Engineering \& Technology College which is affiliated to JNTU Kakinada University, Chirala. 
International Journal of Hybrid Information Technology

Vol.7, No.4 (2014)

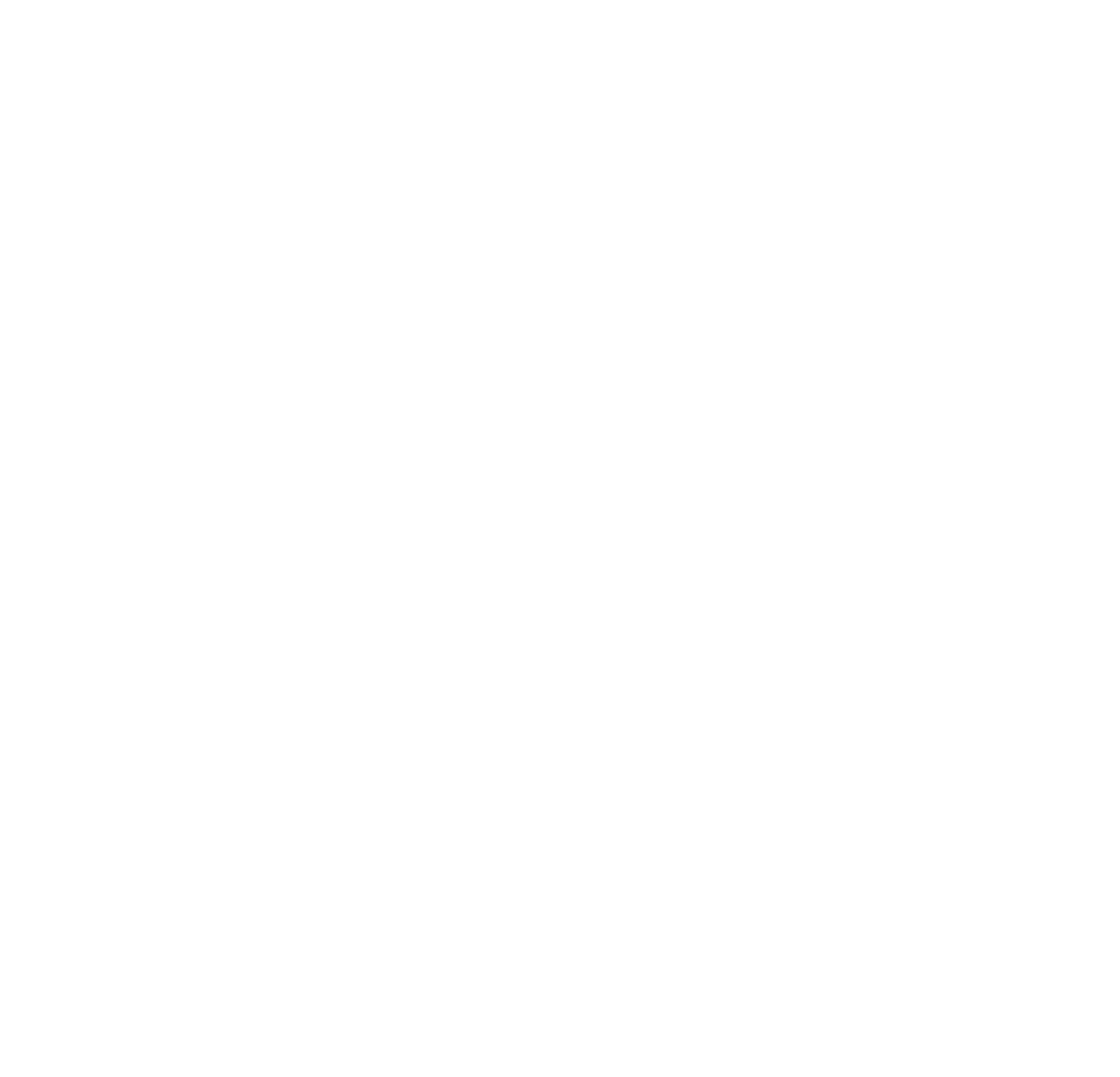

